\title{
Futures Quantitative Trading Strategies Based on Market Capital Flows
}

\author{
Qiao-Xu Qin ${ }^{1}$, Geng-Jian Zhou ${ }^{1}$,Wei-Zhou Lin ${ }^{2}$ \\ ${ }^{1}$ Finance Department of International Business School, Jinan University, Zhuhai, China \\ ${ }^{2}$ Electrical and Information College of Jinan University, Zhuhai, China \\ Correspondence: Qiao-Xu Qin, Finance Department of International Business School, Jinan University, Qianshan Road \\ 206\#, Zhuhai City, Guangdong Province, Post No.519070, China.
}

\author{
Received: February 9, 2018 Accepted: February 26, $2018 \quad$ Available online: February 27, 2018 \\ doi:10.11114/aef.v5i2.3008 URL: https://doi.org/10.11114/aef.v5i2.3008
}

\begin{abstract}
The purpose of this paper is to establish a futures quantitative trading strategy based on the characteristics of capital flows in the futures market and the factors that influence the Futures rate of return. Firstly, PCA and logistic regression are used as the theoretical basis to analyze the characteristics of future futures with high turnover rate and futures yield in the future, and summarize the characteristics of rotation, continuity and similarity of the capital flow in the futures market. Then combining with the characteristics of the flow of futures funds and the idea of taking profit and stop loss, we establish the quantitative trading strategy of futures. Using the partial futures data from 2014-2015 for back testing, the strategy returns better and provides a new investment perspective for the futures market investors.
\end{abstract}

Keywords: quantitative trading, capital flows, investment strategy, full stop

\section{Introduction}

\subsection{Background Description}

In 2016, the global asset management scale reached 80 trillion US dollars. PricewaterhouseCoopers expects global asset management to reach $\$ 100$ trillion in 2020 and $\$ 400$ trillion in 2050 .

Quantified investment refers to the way of trading through quantitative methods and computer programs that issue orders for the purpose of gaining a stable income. It is mainly through the investment philosophy expressed through the mathematical model, and then generated by the computer trading strategy. Quantitative investment is a combination of technologies. In the process of strategy formulation, knowledge of mathematics, geometry, psychology and even bionics is usually used to achieve timing trading, stock selection, statistical arbitrage and risk avoidance. Quantitative transactions to some extent overcome the weakness of human nature, make people more rational. More and more scholars think that quantitative trading will be the most important way to deal with financial markets in the future.

At present, the field of quantitative investment in China is still in its infancy, mainly due to its small amount of funds for quantitative investment and its quantitative strategy. On the other hand, the scope of China's futures is rapidly expanding. There are totally more than 50 varieties in the futures market, and investors are also gradually growing. The requirements for investment are gradually increasing. Some of the larger financial institutions predict that China's asset management market has great potential for growth. For example, McKinsey \& Company estimates that China is likely to become the fastest growing asset management market in the world. Therefore, China's quantitative trading has a lot of room for growth.

\subsection{Relevant Scholarship}

In the stock market, accurately forecasting the market price and obtaining more stable revenue has always been the focus of attention.

People get started investing in securities on the basis of fundamental analysis and technical analysis. Later, Markowitz (Markowitz,1952) put forward the theory of portfolio, people began to pay attention to the time series. On this basis, Sharpe (Sharpe,1964) proposed a capital asset pricing model (CAPM). Ross (Ross,1976) extended CAPM and proposed Arbitrage Pricing Theory (APT). Later, the ARMA model proposed by Jenkins and Box (Jenkins\&Box,1994) and the GARCH model proposed by Bollersllev (Bollersllev,1986) became typical representations of price volatility in the stock market. Madhavan (Madhavan,2002) developed the VMA strategy, which combines price forecasts, averages, and trend 
trackers to predict the short-term trend of a topic. Ekkehart Boehmer and Julie Wu (Ekkehart Boehmer\&Julie Wu,2009) argue that short selling increases the efficiency of price information through empirical evidence and conclude that further research (Ekkehart Boehmer\&Julie Wu,2012) that the pricing is more accurate when active participants are more often. In 2011, Breidt developed an all-pass model based on the ARMA model, which works well for fitting financial time series. Feng Yu-mei, Chen Xuan et al. (Feng.Y. M., Chen. X., \& Zhang. L,2001) studied the impact of volatility in China's stock market on the trading mechanism of margin trading by using vector auto-regressive (VAR) method. The VAR model of margin trading and stock market volatility was established, and the effect of margin on the volatility before and after the stock market volatility was investigated.

The flow of funds is an important indicator of quantitative investment analysis. The flow of funds can reflect the degree to which some futures are sought after, i.e., the supply and demand of futures. Bennet and others to New York stock as the object of study, the use of empirical analysis of stock capital flows and the relationship between stock returns. Frazzinni from the perspective of individual investors, such as the impact of capital flows on the rate of return, the use of common financial flows as a measure of personal preference for stocks. Stefano Fiorenzani (Stefano,2006) systematically addresses risk control in quantitative trading and believes that the risks in trading can be controlled through advanced mathematical and statistical methods.

\subsection{Research Design}

A representative index in the futures market is the capital flow, which can reflect the current market demand or supply of excess stock. Now that the application of capital flow is becoming more and more common, the research shows that the flow of funds has a predictive effect on the return of stocks. By studying the flow of funds, future returns can be predicted.

This article, starting from the futures market itself, establishes a trading strategy by studying the futures market's own rules and based on the flow of futures funds. Based on the theory of PCA and logistic regression, this paper studies the relationship between the futures transaction amount and the basic characteristics of the futures, and then analyzes the future relationship between the futures return rate and the current capital flow and the current return rate, then summarizes the characteristics of the capital flow in the futures market, Futures market itself has the relationship and characteristics of trading strategy, while adding the idea of only profit and stop loss. Then we use the data from January 1, 2014 to December 31, 2015 to conduct back testing to evaluate the effect. Finally, evaluate the results and trading strategies.

\section{Theory and Model Preparation}

\subsection{Formula Improvement}

First, define the formula to calculate the capital flow, Bennett proposed a classic calculation model, the model is based on the market price of the transaction to determine the flow of funds into and out. The specific model is as follows:

$$
\text { Money Flow }=\sum_{i=1}^{n}\left(\text { Volume }_{i}\right)\left(P_{i}\right) \frac{P_{i}-P_{i-1}}{\left|P_{i}-P_{i-1}\right|}
$$

Taking into account the factors of price fluctuation, the rate of change of average transaction price is added to the formula to consider the influence of price fluctuation on the capital flow, and define a capital flow formula that is more suitable for the futures market. The price change rate $(\triangle \mathrm{ATP})$ of the i-th minute transaction is used to replace the average transaction price so as to add the effect of price fluctuation.

This draws the futures market flow of funds formula:

$$
\text { Money Flow }=\sum_{i=1}^{n}\left(\frac{P_{i}-P_{i-1}}{\left|P_{i}-P_{i-1}\right|}\right)\left(\text { Volum }_{i}\right) \frac{\left(P_{i}-P_{i-1}\right)}{\left(P_{i-1}\right)}
$$

Volume $_{i}$ is the volume of goods in $i$ minutes. $P_{i}$ is the transaction price of the $i-t$ th minutes of the commodity. $P_{i-1}$ is the average transaction price for the $i-1$ th minute of the commodity. When dealing with the average transaction price $P_{i}$, we can calculate according to the following formula:

$$
\text { Turnver }=\text { Volume } * \text { Trading price }{ }^{*} \text { Trading unit }
$$

\subsection{PCA Analysis}

The main idea of PCA is to create as few new variables as possible for all the variables originally proposed, so that these new variables are irrelevant to each other, and these new variables retain the original information as far as possible in reflecting the topic information. The purpose of principal component analysis is to reduce the dimensionality of the feature space by a linear combination of features. PCA analysis of the six characteristics in the futures: the opening price, the highest price, the lowest price, closing price, volume, positions, the most influential factors on the futures 
turnover. The core idea is as follows:

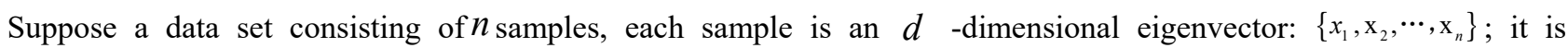
desirable to use a single pattern space point $x_{0}$ to represent the entire sample set, and hope that the distance between the point $x_{0}$ of the selected pattern space and each sample point in the data set is as small as possible. Which is:

$$
\text { Minimize: } J_{0}\left(x_{0}\right)=\sum_{k=1}^{n}\left\|x_{0}-x_{k}\right\|^{2}
$$

Let $m=\frac{1}{n} \sum_{k=1}^{n} x_{k}$ be the average of the sample set.There is:

$$
J_{0}\left(x_{0}\right)=\sum_{k=1}^{n}\left\|x_{0}-x_{k}\right\|^{2}=\sum_{k=1}^{n}\left\|x_{0}-m\right\|^{2}+\sum_{k=1}^{n}\left\|x_{k}-m\right\|^{2}
$$

The vector $m$ that minimizes the mean square error is the mean vector $x_{0}$. The advantage of the sample mean is that the expression is simple, but the disadvantage is that it cannot express the difference between the samples in the set, and the 0 -dimensional representation of the sample set can provide very little information.

If all samples of a sample set are linearly projected through the average vector, we can get a straight line representing the sample set in the sample space, which is called the 1 dimensional expression of the sample set: $x=m+a e$.

In this, $e$ represents the unit vector in the linear direction of the mean; $a$ is a real number scalar, indicating the distance from a point of $x$ to the mean point $m$ of a straight line. Assuming that a point $\left(m+a_{\mathrm{k}} * \mathrm{e}\right)$ on the line is used to represent the sample point $x_{k}$, the square error criterion function of the sample set can be constructed:

$$
J_{1}\left(a_{1}, a_{2}, \cdots a_{3}, e\right)=\sum_{k=1}^{n}\left\|\left(m+a_{\mathrm{k}} * \mathrm{e}\right)-x_{k}\right\|^{2}
$$

The optimal solution of the criterion function:

$$
J_{1}\left(a_{1}, a_{2}, \cdots a_{3}, e\right)=\sum_{k=1}^{n} a_{k}^{2}\|e\|^{2}-2 \sum_{k=1}^{n} a_{k} e^{t}\left(x_{k}-m\right)+\sum_{k=1}^{n}\left\|x_{k}-m\right\|^{2}
$$

Among them, $\|e\|=1$ can get the partial derivative of $a_{k}$ and make the result $0, a_{k}=e^{t}\left(x_{k}-m\right)$ can be obtained for the projection of the vector $x_{k}-m$ in the direction of the line $x=m+a e$. In PCA, the scatter matrix that defines the sample set is:

$$
S=\sum_{k=1}^{n}\left(x_{k}-m\right)\left(x_{k}-m\right)^{t}
$$

As can be seen from the above definition, the scatter matrix is $n-1$ times larger than the sample covariance matrix. Finally, look for the optimal straight line direction $e$, make the square error criterion function $J_{1}$ value minimum.

The above conclusion is extended from 1-D to high-dimensional, using the $d^{\prime}<d$-dimensional feature vector to approximate the d-dimensional vector in the original space:

$$
x=m+\sum_{i=1}^{d} a_{i} e_{i}
$$

Where $e_{1}, e_{2}, \cdots e_{d}^{\prime}$ is the eigenvector corresponding to the $d^{\prime}$ largest eigenvalues of the scatter matrix $S$, and the vectors are orthogonal to each other and form the basis vector of the $d^{\prime}$-dimensional space. And the coefficient $a_{i}$ is the coefficient of the vector $x$ corresponding to the base $e_{i}$, called Principal Component.

The typical steps to actually process the data are as follows:

(1) Standardize the raw data:

Suppose the sample observation data matrix is $X=\left[\begin{array}{cccc}x_{11} & x_{12} & \cdots & x_{1 p} \\ x_{21} & x_{22} & \cdots & x_{2 p} \\ \vdots & \vdots & \ddots & \vdots \\ x_{n 1} & x_{n 2} & \cdots & x_{n p}\end{array}\right]$

The raw data is normalized as follows: $x_{i j}^{*}=\frac{x_{i j}-\overline{x_{j}}}{\sqrt{\operatorname{Var}\left(x_{j}\right)}}(i=1,2, \cdots, n ; j=1,2, \cdots, p)$

In the above formula $\overline{x_{j}}=\frac{1}{n} \sum_{i=1}^{n} x_{i j} ; \operatorname{Var}\left(x_{j}\right)=\frac{1}{n-1} \sum_{i=1}^{n}\left(x_{i j}-\overline{x_{j}}\right)^{2} \quad(j=1,2, \cdots, p)$ 
(2) Calculate the sample correlation coefficient matrix

The normalized correlation coefficient is $R=\left[\begin{array}{cccc}r_{11} & r_{12} & \cdots & r_{1 p} \\ r_{21} & r_{22} & \cdots & r_{2 p} \\ \vdots & \vdots & \ddots & \vdots \\ r_{p 1} & r_{p 2} & \cdots & r_{p p}\end{array}\right]$

In the above formula $r_{i j}=\operatorname{cov}\left(x_{i}, x_{j}\right)=\frac{\sum_{k=1}^{k=n}\left(x_{i}-\overline{x_{i}}\right)\left(x_{j}-\overline{x_{j}}\right)}{n-1}, n>1$

(3) Calculate the eigen values and eigenvectors of the correlation coefficient matrix

Eigen values: $\lambda_{1}, \lambda_{2}, \cdots, \lambda_{p}$

Eigenvectors: $a_{i}=\left(a_{i 1}, a_{i 2}, \cdots, a_{i p}\right), i=1,2, \cdots p$

(4) Select the principal component and write the principal component expression

According to the total contribution of each principal component of the size of the selected $k$ principal components, that is

(5) Calculate the main component score

$$
\text { Contribution rate }=\frac{\lambda_{i}}{\sum_{i=1}^{p} \lambda_{i}}
$$

Substituting the normalized raw data into the principal component expression yields the scores for each principal component, as follows:

$$
\left[\begin{array}{cccc}
F_{11} & F_{12} & \cdots & F_{1 k} \\
F_{21} & F_{22} & \cdots & F_{2 k} \\
\vdots & \vdots & \ddots & \vdots \\
F_{n 1} & F_{n 2} & \cdots & F_{n k}
\end{array}\right]
$$

In the above formula. $F_{i j}=a_{j 1} x_{i 1}+a_{j 2} x_{i 2}+\cdots a_{j p} x_{i p}, i=1,2, \cdots, n ; j=1,2, \cdots, k$

\subsection{Logistic Regression Model}

In general linear models, Dependent variables have practical meaning. However, When the dependent variable $\beta$ is a two-class or $0-1$ variable, it has no practical significance. $\beta$ is a random variable of Bernoulli distribution. Which means $\beta \sim b(n, p)$, for $0-1$ variables, The regression model is improved as follows:

(1) Change the regression function to a continuous curve with a range of [0 1], Among so many functions, the most widely used is logistic, In the form of

$$
\beta=\frac{1}{1+e^{-x}}=\frac{e^{x}}{1+e^{x}}
$$

(2) The dependent variable $\beta$ only takes a value of 0 or 1 ,so it can't be a dependent variable in a regression model. We suppose that $P$ is the probability of $\beta=0, \mathrm{Q}=1-\mathrm{P}$ is the probability of $\beta=1$. Q is the probability of $\beta=1$. When we observe the variables, we use $\left(x_{1}, x_{2}, \cdots, x_{p}\right)$ to show the variables observed. The actual observation results show that the relationship between probabilistic and explanatory variables is not linear, but "S" curve. This is because the probability distribution function is a "S" type curve. The Logistic function is a curve of "S" type. Therefore, the Logistic curve is generally used to describe the relationship between $\mathrm{X}$ and the explanatory variable $\mathrm{x}$.

Use logit transformation on the formula, we can get

$$
\begin{gathered}
P=P(\beta=1 \mid X)=\frac{\exp \left(\alpha_{0}+\alpha_{1} x_{1}+\cdots+\alpha_{p} x_{p}\right)}{1+\exp \left(\alpha_{0}+\alpha_{1} x_{1}+\cdots+\alpha_{p} x_{p}\right)} \\
\log i t(\beta)=\ln \left(\frac{p}{1-p}\right)=\alpha_{0}+\alpha_{1} x_{1}+\cdots+\alpha_{p} x_{p}=X \beta
\end{gathered}
$$

The model above is called the logistic regression model, and $\beta_{0}, \beta_{1}, \cdots, \beta_{p}$ are the parameters to be estimated. 


\section{(3)Establishment of Logistic Model}

From the previous analysis, we can know that the future price of futures has a certain relationship with the flow of funds. To further quantify the relationship between them, we combine the logistic model with the flow of money and establish a new model as follows:

$$
\operatorname{Logit}(y)=\ln \left(\frac{p_{t+m, i}}{1-p_{t+m, i}}\right)=\alpha_{0}+\alpha_{1} \times \text { Moneyflowt, } i
$$

$\mathrm{Pt}+\mathrm{m}, \mathrm{i}$ is the probability of a futures price rising after $\mathrm{m}$ minute at $\mathrm{t}$ moment, Moneyflowt, $\mathrm{i}$ represents the flow of money to futures $\mathrm{I}$ at $\mathrm{t}$ time. 1-Pt+m,i indicates the probability that futures I will fall after $\mathrm{m}$ minutes at $\mathrm{t}$ moment.

\section{Empirical Analysis}

\subsection{Empirical Analysis of PCA}

Using the historical data of commodity futures from January 1, 2011 to December 31, 2013 provided by Shenzhen Digital Kinetic Information Technology Co., Ltd., the above, PCA statistical model is used to analyze the characteristics of the futures market. Based on the analysis of the results, Five types of futures relatively large factors such as table:

Table 1. Five types of futures relatively large factors

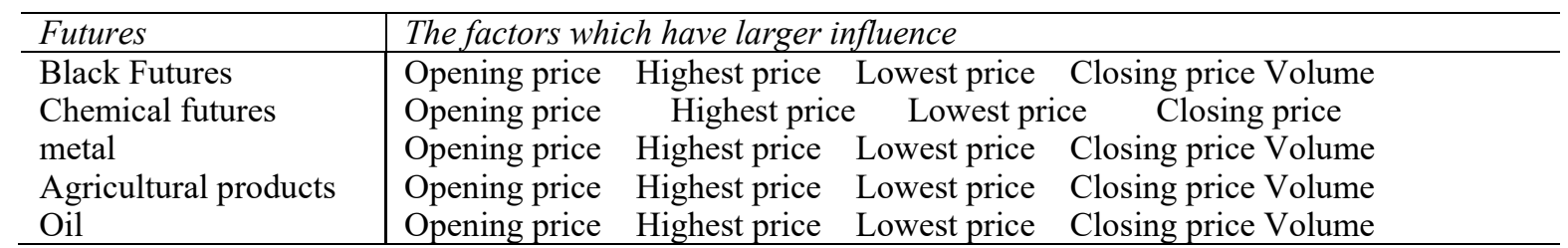

By analyzing the trend of the opening price, the closing price, the highest price, the lowest price, the trading volume, the open interest and the turnover of each futures, the trend of the opening price, the highest price, the lowest price and the closing price is similar. There is a linear relationship between the amount and the volume of transactions, according to the above can know the volume and position also has a very close relationship, therefore, can be obtained, on Turnover Influence largest eigen value is closing price, trading volume and positions.

\subsection{Empirical Analysis of Logistic Model}

In this paper, using the last 1000 data of each futures contract from 2011 to 2013, using the last 40 data as the test set and the previous data as the training set, a logistic regression model is established to analyze the relationship between the capital flow in the futures market and the price of the future futures. Because there are many possible values of $\mathrm{m}$, there are a variety of analytical results, due to space limitations, only $m=1$ for the analysis.

Table 2. Calculation results

\begin{tabular}{llll}
\hline Futures code & Accuracy & The value of $\mathrm{P}$ & $\begin{array}{l}\text { Regression } \\
\text { coefficients }\end{array}$ \\
\hline j0000 & $65.20 \%$ & $4.15 \mathrm{E}-11$ & $8.56 \mathrm{E}-11$ \\
rb0000 & $64.50 \%$ & $5.20 \mathrm{E}-09$ & $6.92 \mathrm{E}-07$ \\
fg000 & $72.90 \%$ & $3.17 \mathrm{E}-08$ & $6.29 \mathrm{E}-11$ \\
i0000 & $75.40 \%$ & $7.10 \mathrm{E}-32$ & $1.60 \mathrm{E}-10$ \\
ru0000 & $75.30 \%$ & $3.07 \mathrm{E}-33$ & $4.29 \mathrm{E}-11$ \\
ag0000 & $71.90 \%$ & $8.80 \mathrm{E}-09$ & 0.000001 \\
au0000 & $87.60 \%$ & $1.17 \mathrm{E}-26$ & $5.07 \mathrm{E}-08$ \\
cu0000 & $79.10 \%$ & $1.12 \mathrm{E}-31$ & $5.69 \mathrm{E}-11$ \\
pb0000 & $81.70 \%$ & $3.81 \mathrm{E}-07$ & $2.50 \mathrm{E}-08$ \\
a0000 & $79.00 \%$ & $1.50 \mathrm{E}-22$ & $1.20 \mathrm{E}-09$ \\
b0000 & $82.76 \%$ & $7.63 \mathrm{E}-15$ & 0.000004 \\
c0000 & $82.80 \%$ & $7.63 \mathrm{E}-15$ & 0.000004 \\
cf000 & $63.50 \%$ & $3.08 \mathrm{E}-09$ & $2.99 \mathrm{E}-11$ \\
m0000 & $81.40 \%$ & $8.52 \mathrm{E}-29$ & $2.46 \mathrm{E}-10$ \\
sr000 & $76.40 \%$ & $5.93 \mathrm{E}-30$ & $1.97 \mathrm{E}-10$ \\
oi000 & $65.10 \%$ & 0.000001 & $9.02 \mathrm{E}-10$ \\
y0000 & $78.90 \%$ & $9.16 \mathrm{E}-43$ & $2.79 \mathrm{E}-10$ \\
\hline
\end{tabular}

The regression results show that in the black plate, metal plate, the chemical sector, the agricultural sector and the oil sector, the prediction accuracy is above $50 \%$, and the test result of the $\mathrm{P}$ parameter value is less than 0.05 , through the test, for the futures we selected, with cash flow to predict commodity futures prices the accurate rate of change, most cases are $50 \%$, so the flow of funds through the futures price prediction is feasible. 


\subsection{Empirical Analysis of Futures Market Characteristics}

In order to analyze the characteristics of the futures market, we combine the monthly data extracted to get the change over time of the average price of each type of futures, as shown in the figure below (at 3-month intervals).

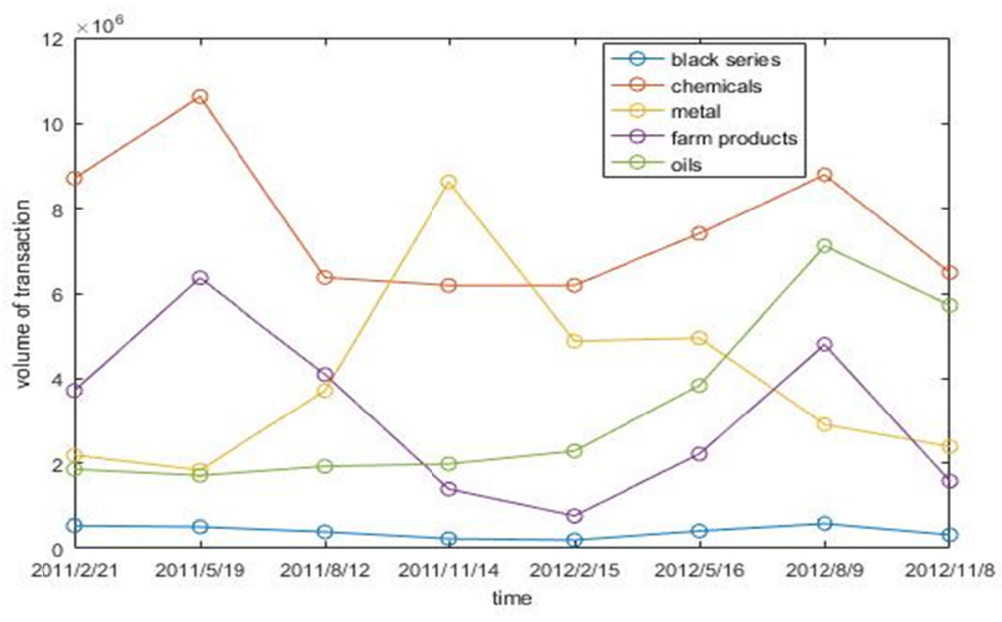

Figure 1. Average price of each type of futures

According to the analysis of the price trend of the five futures in the picture, we can sum up the kinds of futures which are mainly promoted by the different time.

Table 3. Different periods to promote the broader market rose futures

\begin{tabular}{l|l}
\hline Time & Futures which mainly promote the market \\
\hline The first half of 2011 & Metal, chemical, black futures \\
The second half of 2011 & Agricultural products, black futures \\
The first half of 2012 & Agricultural products, black futures \\
The second half of 2012 & Oil, metal \\
The first half of 2013 & Black, chemical futures \\
The second half of 2013 & Oil, Chemical futures \\
\hline
\end{tabular}

\section{Conclusion:}

(1) As can be seen from the table, in each of the six months, the types of futures that promote the price rise of the entire futures market are different. The various types of futures prices turn up to promote the entire futures market. Based on this phenomenon, it can be concluded that the futures market has wheel mobility.

(2) At the same time, It can be seen from the trend of each type of futures that, in most cases, when the average price of a class of futures rose or fell, in the next period of time, the other types of futures average transaction price appear the same trend in a way. It can be analyzed from this phenomenon that several types of futures trading average price movements have a similarity, which is reflected in the similar trend of several types of futures. It can be derived that the futures have a feature of similarity.

(3) Judging from the figure, when the average price of futures transaction changes, no matter what kind of change, this change will continue for some time and not in a very short period of time for another change. That is, the flow of funds in a few days have the same trend and you can judge the flow of funds in a persistent characteristics.

It is the same as the PCA analysis method used earlier in this article. The results are as follows: the results are as follows: MATLAB is used to solve the kind of futures which can be affected by the average capital flow of each kind of futures in each category of futures.

Table 4. Factors influencing each section

\begin{tabular}{l|l}
\hline Futures Sector & Influential Species \\
\hline Metal & Each futures have the same effect \\
Agricultural Products & Soybean Two、Cotton、Soybean meal、White sugar \\
Chemical futures & Each futures have the same effect \\
Black Futures & Rebar \\
Oil & Each futures have the same effect \\
\hline
\end{tabular}

According to the conclusion of the table, we can see that the varieties of futures that have a great influence on the capital flow and the yield of each type of futures can gain more profits by increasing the trading volume or positions when formulating strategies.. 


\section{Trading Strategy}

\subsection{Model Selection}

Through regression analysis, we find that the future price of futures has the largest relationship with the closing price, volume, and open interest. Therefore, the quantitative trading strategy is based on the changes in closing price, volume and position. In practice, we usually start to trade on the basis of the current closing price, volume, position and the average value of each volume in a certain period of time, as well as the relative relationship between the short-term price and the long-term price. Therefore, based on the short-term price trend, we build a quantitative trading model based on the relationship between the closing price, volume, open interest and the corresponding mean value.

\subsection{The Establishment of the Model}

Calculate the relevant parameters to get the mean of each correlation variable:

(1) $x_{4 n}$ is the average of the closing price within $n$ days

(2) $x_{5 n}$ is the average of the daily turnover within $n$ days

(3) $x_{6 n}$ is the average of the amount of days within $n$ days

(4) Short-term closing price of the average ( $N_{1}$ days)

(5) Long-term closing price of the average ( $N_{2}$ days)

\subsection{Trading Logic}

In the case of $x_{L}>x_{S}$, when $x_{4}>x_{4 n}, x_{5}>x_{5 n}, x_{6}>x_{6 n}$, if a trader was holding short positions,should first close positions, and then open long positions; if there is no position, then open direct long positions ;

In the case of $x_{L}<x_{S}$, when $x_{4}<x_{4 n}, x_{5}>x_{5 n}, x_{6}<x_{6 n}$ when a trader holds a warehouse at the time,should first open the position and open the empty position; if there is no position, should open the position directly;

In the first case, the closing price, volume, positions are greater than its corresponding $n$-day moving average, indicating that the market confidence in the kind of goods is sufficient, at the same time, due to short-term average price in the long-term average price, so the probability of reversing the price trend is very large, the probability of profit is relatively large;

In the second case, the closing price, volume, positions are under the n-day moving average, indicating that the market investors are not optimistic about its future market, and its price has been high, then the short is relatively easy to be triggered. The probability of profit is relatively small. Therefore, investors in the use of strategy, on the one hand can refer to the best parameters of the historical data test, on the other hand, can adjust the value of the $n, N_{1}, N_{2}$ according to the potential judge, or from other large cycle of technical indicators ;

\subsection{Capital Management and Stop Loss or Profit}

According to the logic of the strategy, after buying a commodity futures, if the market price can be in accordance with the expected increase in the strategy, you can profit. However, any kind of commodity, its market prices will be affected by the impact of the market fluctuations, If you have not closed before the price trend changes, it is likely to suffer a relatively large loss; At the same time, if we don't close the position before the price trend turned, we will miss the opportunity for profit. In order to maintain the overall rate of return, it is necessary to control the position of the trading strategy and increase the stop-loss strategy, in the pursuit of high returns while reducing risk. Therefore, this paper takes ATR as the reference parameter to control the position and stop the loss.

(1) Introduction to ATR

ATR, full name Average True Range, the average of real fluctuations, is used to measure the degree of market price fluctuations indicators. ATR indicators were mainly used in commodity markets in the early days. In general, the direct use of the highest price and the lowest price correlation to measure the degree of market volatility indicators cannot fully reflect the degree of market volatility, and ATR indicators are a good solution to this problem.

Indicators are mainly used to measure price fluctuations. Therefore, this technical indicators cannot directly reflect the price trend and its trend stability, but only that the volatility of the price volatility. It also truly reflects the market participants' mood swings.

\section{(2) Calculation method of ATR}

Today's amplitude, today's highest and yesterday's closing price, today's lowest and yesterday's difference in the maximum value of the real volatility, in the real volatility, you can use a period of time to calculate the average ATR. The length of time used in the calculation can be set according to different trading strategies,. It can be set for 10 days, 20 days or even 65 days. 


\section{(3) Advantages of ATR indicators}

The market conditions in different periods of volatility is difference, if we use fixed-point stop-loss method, that is, setting a price as a stop appearance criteria, there will be a lack of flexibility and adaptability, it is difficult to cope with uncertainty of the market, while the ATR indicator is a dynamic value that can automatically adapt to changes in the market.

(4) ATR in the application of trading strategies

When the price is $r *$ ATR higher than that when opening the position, you can consider continuing to buy more. That is, if the direction of the positions is more; or position is empty, the price is $r *$ ATR lower than the previous price, you can consider continuing to buy more.

\section{Model Application}

According to the above strategy logic, we use MATLAB software to write a quantitative trading strategy code, and back set in Shenzhen Digital Energy Information Technology Co., Ltd. developed Auto-Trader platform with the data from January 1, 2014 to December 31, 2015.We have finally selected glass, cotton, soybean meal, silver, copper, natural rubber, refined terephthalic acid as the subject of strategic transactions. The results of the test are as follows:

Table 5.Strategy Performance Summary

\begin{tabular}{l|l}
\hline Indicator & The Value of the Indicator \\
\hline Initial capital & 100000000 \\
Initial rate of return on capital(\%) & 152.18 \\
Net income & 152176583.56 \\
Gross profit & 785501443.93 \\
Hair loss & -633324860.3663 \\
Profit factor & 1.2403 \\
Bull net income & -35315075.0134 \\
Bear net income & 187491658.5761 \\
Arithmetic annualized rate of return(\%) & 78.42 \\
Geometric annualized rate of return(\%) & 61.07 \\
Maximum retracement & 49653231.5206 \\
Maximum retracement rate & $17.12 \%$ \\
\hline
\end{tabular}

Table 6.Strategic Performance Ratio

\begin{tabular}{l|l}
\hline Indicator & The Value of the Indicator \\
\hline Sharp ratio & 1.5485 \\
Calmar ratio & 3.4502 \\
Sortino ratio & 3.2813 \\
Net income or Maximum Potential loss & 2.4778 \\
Net income or fee & 0.3290 \\
\hline
\end{tabular}

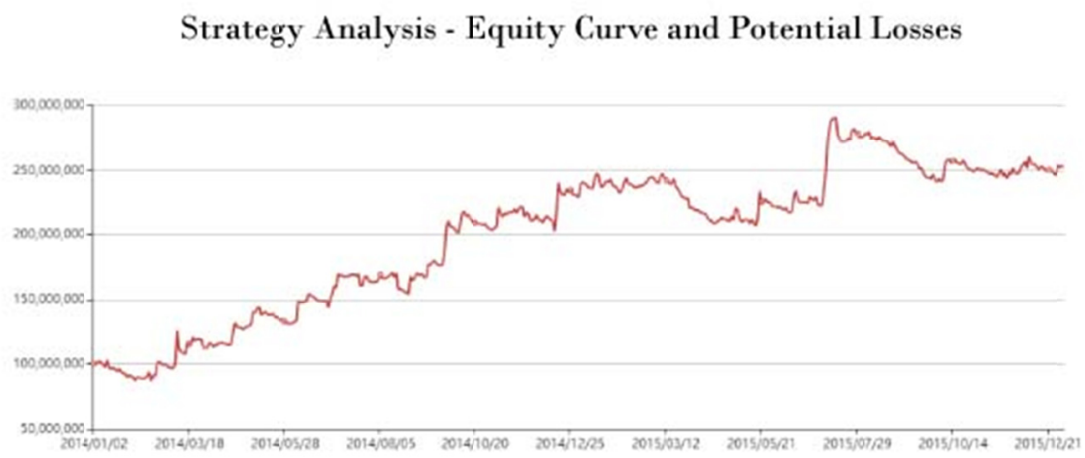

Figure 2. The Total Profit Curve

We can see that the trading strategy can be used in the glass, cotton, soybean meal, silver, copper, natural rubber, refined terephthalic acid on the seven goods can get good returns, and the retracement rate of $17 \%$, Sharp ratio of 1.5485 , indicating that the risk of this trading strategy is small, while each bear a unit of the total risk, the excess compensation is not low, and the equity curve has grown steadily. The strategy reached a low risk and high profit expectations, achieving the steady growth of assets. 


\section{Conclusion}

Due to the weak predictive ability of traditional prediction methods, this paper applies statistical theory to predict the characteristics and influencing factors of stock market, and constructs quantitative trading strategy. The strategy is then measured back with the futures data from January 1, 2014 to December 31, 2015. Based on the characteristics of futures market and the idea of stopping profit and stop loss, the quantitative trading strategy is constructed. The following conclusions are drawn:

(1) The futures market has the nature of rotation. The various kinds of futures prices have been rising to promote the whole futures market. The futures market has the similarity, and the trend of the trade average of several kinds of futures has a close correlation. The flow of funds in the futures market is persistent, and this change will continue for a period of time when the average price of the futures is changed. When making trading strategies, we can make quantitative decisions, such as quantitative selection, quantitative timing, stock index futures arbitrage, commodity futures arbitrage, statistical arbitrage, algorithm transactions, asset allocation, risk control and so on.

(2) Futures futures return rate and current return rate and current transaction average price are related to the characteristics of futures market, that is, we can estimate future futures yield from some indicators of current futures market to a certain extent. For investors, more information should be mastered when investing. The more information you know, the more accurate, it may be when you make a judgment.

(3) When investors make investment decisions, they can start from the investment objects themselves, and invest through studying some rules and relationships of the investment objects. This investment mode can often get good results, which is the basic breakthrough point of this paper.

In general, the principle of the model is simple, easy to operate, and practical, easy to promote. Using PCA analysis and logistic regression to analyze the characteristics of the futures market, we can improve the strategy stability through the stop-loss only. However, there are some shortcomings in the model established in this paper. For example, the prediction accuracy may not be high due to the limitations of the algorithm itself. In order to calculate the simple ignored the policy changes, the mentality of investors and other factors. Therefore, the model is idealized.

\section{References}

Bennett, J. A., Richard, W. S. (2001). Can Money Flows Predict Stock Return? Financial Analyst Journal, 2001(12), 64-77. https://doi.org/10.2469/faj.v57.n6.2494

Bollerslev, T. (1986). Generalized autoregressive conditional heteroskedasticity. Eeri Research Paper, 31(3), 307-327. https://doi.org/10.1016/0304-4076(86)90063-1

Box, G. E. P., \& Jenkins, G. M. (1995). Time series analysis: forecasting and control. Technometrics, 68(2), 303-303. https://link.springer.com/chapter/10.1057/9781137291264_6

Breidt, F. J, Davis, R. A., \& Trindade, A. A. (2001). Least Absolute Deviation Estimation for All-Pass Time Series Models. Annals of Statistics, 29(4), 919-946. https://doi.org/10.1214/aos/1013699986

Dewey. (2016). Study on risk Prevention Strategy of Bank Asset Management.Chinese market, 14), 96-97.https://core.ac.uk/display/41431500

Feng, Y. M., Chen, X., \& Zhang, L. (2015). Research on the impact of margin trading on the volatility of China's stock market -- Based on the comparison test before and after the transfer of securities and loans. Shandong Social Sciences, (2), 130-134.

Financial Network. Price Waterhouse Coopers. (2014).Global assets under management will exceed $\$ 100$ tillion by 2020 [EB/OL]. (2014-3-26) from http://www.creader.com/news/20011219/200112190019.htmi.

Fiorenzani, S. (2006). Quantitative methods for electricity trading and risk management. Finance \& Capital Markets, 2006. https://doi.org/10.1057/9780230598348

Frazzini, A., Lamont, O. A. (2008). Dumb Money: Mutual Fund Flows and the Cross-Section of Stock Returns.Journal of Financial Economics, 88, 299-322. https://doi.org/10.1016/j.jfineco.2007.07.001

Gang, L., Zhipeng, C. (2015). Research on Optimization of capital flow direction in Chinese stock market based on quantitative analysis.Journal of Tianjin commercial university. 35(05), 23-27.

Jin, W. Z. (2014). Application of MATLAB in Mathematical Modeling (2nd ed.), (2), 39-41

Jingjuan, L. (2005). Multivariate linear regression model test method. Journal of Hunan Tax College, (05), 49-50+60.

Madhavan, A. N. (2002). VWAP strategies. Trading, (1), 32-39. https://www.researchgate.net/publication/285344023_VWAP_strategies 
Markowitz, H. M. Portfolio Selection - Markowitz, H. M. - Yale University Press. https://yalebooks.yale.edu/

Ross, S. A. (2015). The arbitrage theory of capital asset pricing. Journal of Economic Theory, 13(3), 341-360. https://doi.org/10.1016/0022-0531(76)90046-6

Sharpe, W. F. (1964). Capital asset prices: a theory of market equilibrium under conditions of risk. The Journal of Finance, 19(3), 425-442. https://doi.org/10.1111/j.1540-6261.1964.tb02865.x

Wei, H., Li, C., Xie, J., \& Dai, G. E. (2010). Xinyuan.Analysis on the trend of Capital flow in A Stock Market.Stock market guide,(11), $72-77$.

$\mathrm{Wu}$, J. (2010). Short selling and the informational efficiency of prices. Texas A \& M University, 2010.

Xue, H. G., Cheng, X. X. U., San, P. L. I., et al. (2005). The Sensitivity Analysis in Calculating the Portfolio's VaR Based on Principal Component Analysis. Chinese Journal of Engineering Mathematics, 22(5).

Zhonggeng, H. (2014). Mathematical Modeling method and its Application.Beijing. Higher Education Press, 140-143.

\section{Copyrights}

Copyright for this article is retained by the author(s), with first publication rights granted to the journal.

This is an open-access article distributed under the terms and conditions of the Creative Commons Attribution license which permits unrestricted use, distribution, and reproduction in any medium, provided the original work is properly cited. 